Open Access

\title{
Caesarean delivery and its correlates in Northern Region of Bangladesh: application of logistic regression and cox proportional hazard model
}

\author{
Mostafizur Rahman ${ }^{1 *}$, Asma Ahmad Shariff ${ }^{2}$, Aziz Shafie ${ }^{3}$, Rahmah Saaid ${ }^{4}$ and Rohayatimah Md. Tahir ${ }^{2}$
}

\begin{abstract}
Background: Caesarean delivery (C-section) rates have been increasing dramatically in the past decades around the world. This increase has been attributed to multiple factors such as maternal, socio-demographic and institutional factors and is a burning issue of global aspect like in many developed and developing countries. Therefore, this study examines the relationship between mode of delivery and time to event with provider characteristics (i.e., covariates) respectively.

Methods: The study is based on a total of 1142 delivery cases from four private and four public hospitals maternity wards. Logistic regression and Cox proportional hazard models were the statistical tools of the present study.

Results: The logistic regression of multivariate analysis indicated that the risk of having a previous C-section, prolonged labour, higher educational level, mother age 25 years and above, lower order of birth, length of baby more than $45 \mathrm{~cm}$ and irregular intake of balanced diet were significantly predict for C-section. With regard to survival time, using the Cox model, fetal distress, previous C-section, mother's age, age at marriage and order of birth were also the most independent risk factors for C-section. By the forward stepwise selection, the study reveals that the most common factors were previous C-section, mother's age and order of birth in both analysis. As shown in the above results, the study suggests that these factors may influence the health-seeking behaviour of women.
\end{abstract}

Conclusions: Findings suggest that program and policies need to address the increase rate of caesarean delivery in Northern region of Bangladesh. Also, for determinant of risk factors, the result of Akaike Information Criterion (AIC) indicated that logistic model is an efficient model.

Keywords: Caesarean delivery, Risk factors, Logistic regression, Cox model, AIC, Bangladesh

\section{Background}

Delivery may occur either by caesarean or non-caesarean. A multiple factors associated with safe delivery practices, ranging from demographic to socio-economic [1]. More than $70 \%$ of the deliveries took place at home, and only $32 \%$ birth in Bangladesh were under safe and hygienic conditions [2]. In recent years, caesarean delivery is one of the most common surgical procedures. Caesarean sections (C-section) are more common among first births (12.7\%), births in urban areas (15.9\%), and especially among births in the private sector $(67.3 \%)$, whereas the public sector

\footnotetext{
*Correspondence: mos_pshd@yahoo.com

'University of Rajshahi, Rajshahi, Bangladesh

Full list of author information is available at the end of the article
}

was (34.6\%) [2]. The rate of C-sections is increasing in Bangladesh. In 2001, only $2.6 \%$ of births were delivered by C-section, compared with $12.2 \%$ in 2010 [3]. The number of caesarean delivery has also been growing in many developed and developing countries $[4,5]$ and this increase has not been clinically justified [6]. Over the last few years, the rates of $\mathrm{C}$-section have risen substantially in many countries such as Brazil (30\%), [7] Chile (40 \%), [8] USA (24.4\%) [9] and Malaysia (15.7 \%) [10]. According to WHO, there is no justification for any region to have a caesarean rate higher than $10-15 \%$. This signifies a serious cause for concern in most of the countries in the world and due to several investigations into

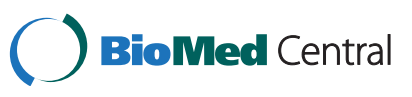

(c) 2015 Rahman et al. This is an Open Access article distributed under the terms of the Creative Commons Attribution License (http://creativecommons.org/licenses/by/4.0), which permits unrestricted use, distribution, and reproduction in any medium, provided the original work is properly credited. The Creative Commons Public Domain Dedication waiver (http:// creativecommons.org/publicdomain/zero/1.0/) applies to the data made available in this article, unless otherwise stated. 
the reasons for the rising rates in caesarean delivery, it is now identified as emerging "global epidemic" [11, 12].

The increase in caesarean deliveries has been attributed to multiple factors ranging from maternal, sociodemographic and institutional factors. Caesarean delivery rates are known to vary widely among different population groups, with known risk factors including maternal age, [13-15] order of birth, [16] baby weight, [17] socioeconomic status, [18] high levels of maternal education, [19-23] previous c-section, [24-26] obstetric complications, [24, 28] maternal request (refers to a primary caesarean delivery performed because the mother requests this method of delivery in the absence of conventional medical or obstetrical indications) [27-29] and high income level [18, 22, 30-33]. The increase in caesarean delivery rates has also raised questions in Bangladesh like in most other countries. Though increased caesarean rates have been questioned and emphasized, for the lack of reliable administrative records, no early studies were carried out to identify the possible risk factors associated with $\mathrm{C}$-section in this country. However, some related studies have been conducted in other countries. This study presents the most recent estimate of $\mathrm{C}$-section delivery in northern region of Bangladesh and examines the association of reported complications around delivery as well as socio-demographic and relevant characteristics of women with $\mathrm{C}$-section using data from sample survey. To investigate the significant relationship between mode of delivery (that is, caesarean or non-caesarean) and covariates (independent variables), most of the studies carried out logistic regression model $[16,18,26,34]$. On the other hand, time (it is measured as after marriage to getting one child or previous child to current child) is one of the factors that may play an important role in C-section but it is not yet considered in other studies. From this point of view, the study also examined the relationship between time to event (that is, caesarean or non-caesarean) and covariates. In these cases, Cox's model is considered to be the most used procedure for modelling the relationship of covariates to a survival or other censored outcomes [35]. Consequently, to obtain a more complete assessment of risk factors, this study considered time as a dependent variable and the concomitant variables (covariates) as independent variables and compared the results of empirical data analyzed by logistic regression and Cox proportional hazard model.

\section{Methods}

\section{Study area}

The study sample comprised of 1142 women who had delivery either by caesarean or non-caesarean delivery at four private and four public hospitals maternity wards in the northern region of Bangladesh during the period of January to March 2010. Among the 1142 delivery cases,
652 were caesarean and the remaining 490 were noncaesarean. The northern region is the part of north in Bangladesh, where the hospitals were situated. The hospitals involved in the study are Islamic bank hospital, Shapla, Rangpur and city clinic which are the private hospitals, while Rajshahi, Bogra, Rangpur and Dinajpur medical college hospitals are expressed as public hospitals. Also, the terms private and public patients refer to respondents, who were admitted in maternity wards for safe delivery in the respective hospitals.

\section{Study population}

Pregnant women in the Northern region of Bangladesh.

\section{Sampling design}

The study followed a cross-sectional design where data were collected by direct interviews. Before delivery, the participants were selected by simple random sampling and proportion to the estimated load of deliveries, which accounted for $60 \%$ of all deliveries during the survey period. Most of the questions were close-ended and the answers chosen by the respondents were indicated by the tic mark. The response rate was $100 \%$.

\section{Measurement of variables \\ Dependent variables}

The dependent variables considered as (i) the types of delivery coded as dichotomous (caesarean $=1$, noncaesarean $=0$ ) and (ii) duration of time (that is, after marriage to getting one child or from previous child to current child) to event (that is, mode of delivery).

\section{Independent variables}

The maternal variables included prolonged labour (more than $12 \mathrm{~h}$ ), fetal distress (it is commonly used to describe fetal hypoxia that is low oxygen levels in the fetus, which can result in fetal damage if the fetus is not promptly delivered), previous c-section, breathing difficulty, child aborted around delivery, multiple births; head circumference, length and weight of babies.

For the analysis of data, the category related to prolonged labour, fetal distress, previous C-section, breathing difficulty, child aborted around delivery and multiple births were assessed as yes or no. The head circumference of newborns was classified into two categories: $<32 \mathrm{~cm}$ and more than $32 \mathrm{~cm}$. The length and weight of baby were categorized into: $<45 \mathrm{~cm}$ or more than $45 \mathrm{~cm}$ and $<2.5 \mathrm{~kg}$ or more than $2.5 \mathrm{~kg}$ respectively. The socio-demographic variables included maternal age at birth, age at marriage, parity (order of birth), and maternal educational level. Maternal age was categorized into four broad groups (years): <20, 20-24, 25-29 and more than 30 . The age at marriage was classified into three categories: $<18$ years, $18-22$ years and 23 years and above. The 
parity was divided into three groups: 1,2 , and $\geq 3$. Education status is the highest level of schooling attained, measured as primary and below (0-5 years), secondary (6-10 years) and higher (11 years and above). Place of residence and duration of taking balance diet (it refers to milk, fish, egg, fruit and vegetables that contains adequate amounts of all the necessary nutrients required for healthy growth and activity and those diets were taken a woman in pregnancy period) were also considered as the other related variables in the study. Additionally, place of residence was classified as rural verses urban and duration of taking balance diet was measured as a categorical variable: often, once a week and rarely.

\section{Statistical analysis}

An initial bivariate analysis was performed to identify significant associations between types of delivery (caesarean vs. non-caesarean) and a series of independent variables. Dichotomous variables were analysed by the $\chi^{2}$ test or Fisher exact test, where appropriate. To determine the risk factors which are associated with the Csection, based on the different criteria, two multivariate techniques were used. They are logistic regression model and Cox proportional hazard model. Logistic Regression and Cox proportional hazard models are the most frequently used for analysing data in epidemiological and clinical studies [38]. The logistic regression is analogous to multiple linear regressions where the dependent measure is dichotomous in nature (coded by the values 0 and 1); whereas the Cox proportional regression model assumes that the effects of the predictor variables (names of variables that we expect to predict survival time) are constant over time. For both techniques, maternal, socio-demographic and other relevant variables were treated as independent variables, while the dependent variables were already mentioned in the above section. The most influential risk factors were estimated separately for overall, public and private hospital by stepwise selection. The value of $P<0.05$ was considered statistically significant. Finally, to identify and measure the risk factors for caesarean delivery, that is, how well the model fits the data, Akaike Information Criterion (AIC) is used. Generally, the AIC formula is -2 $\log (\mathrm{L})+2 \mathrm{k}$, where, $\mathrm{L}$ is the maximized value of the likelihood function for the estimated model and $\mathrm{k}$ is the number of parameters in the statistical model. Lower AIC indicates a better likelihood.

\section{Ethical clearance}

We obtained informed verbal consent from the respondents before conducting the interview.

The study was approved by the ethical board and research review committee of the Dept. of Population
Science \& Human Resource Development, University of Rajshahi, Bangladesh.

\section{Results}

Patient characteristics and significant variables are listed in Table 1. The sample comprised of 1142 mothers with the aggregate caesarean section (C-section) rate among the participants being $57.09 \%$. The C-section rate in the public hospital was $30.28 \%(n=199)$, while the C-section rate in private hospital was $93.47 \%(n=453)$. Caesarean rates varied by level of maternal complications. The significant rate was highest among women having previous C-section $(94.8 \%)$. Similarly, the rate was highest among women with higher education level (76.8\%, compared to $44.8 \%$ for mothers with primary and below level of education) followed by higher maternal ages (30 years and above) as compared to lower age groups (less than 20 years). The same pattern was also observed in age at marriage. Residence and nutritional status were among the factors associated with the likelihood of having $\mathrm{C}$-section. C-section deliveries were of low frequency in urban areas as compared to rural areas. The highest Caesarean rate was observed for those who rarely take a balanced diet (76.0\%). Out of 15 variables examined, eight were statistically significant while the remaining eight were statistically not associated with the type of delivery.

Figure 1 displays the survival for mean values for selected covariates in the Cox model over time by health facilities. The survival curve represents the probability of mothers who have delivery by caesarean at any given time. During the period of below 2 years, the probability of getting first child from the women in private hospital is greater than those who delivered by caesarean in public hospital. Figure 1 also shows that the rate of caesarean cases over time is relatively constant and approximately below $1 \%$ after the duration time of 6 years and above.

The adjusted odds ratios (ORs) and hazard ratios (HRs) (with $95 \%$ confidence intervals) for a C-section are shown in Tables 2, 3 and 4 at overall, private and public hospitals respectively. As shown in Table 2 within overall delivery cases, the binary logistic regression of multivariate analysis indicated that the risk of having previous C-section $(\mathrm{OR}=20.18, \mathrm{CI}=10.46-25.58)$, prolonged labour $(\mathrm{OR}=0.17, \mathrm{CI}=0.12-0.23)$, higher educational level $(\mathrm{OR}=2.68, \mathrm{CI}=1.58-4.54)$, mother's age > 25 years $(\mathrm{OR}=2.74, \mathrm{CI}=1.58-4.72)$, lower order of birth $(\mathrm{OR}=0.74 \mathrm{CI}=0.49-1.12)$, length of baby $>45 \mathrm{~cm}(\mathrm{OR}=$ $1.45, \mathrm{CI}=1.04-2.02$ ), and irregular intake of balance diet $(\mathrm{OR}=1.87 \mathrm{CI}=1.24-2.81)$ significantly predict $\mathrm{C}$-section delivery. The odds ratio 20.18 indicated that the odds of being $\mathrm{C}$-section to the women were seen 20.18 times greater in previous $\mathrm{C}$-section as compared to those were not in previous $\mathrm{C}$-section. The others odds ratio can be explained in the same way. In a Cox's regression 
Table 1 Percentage distributions of maternal, socio-demographic and other characteristics by type of delivery and their significance level in northern region of Bangladesh

\begin{tabular}{|c|c|c|c|c|c|}
\hline \multirow[t]{3}{*}{ Selected variables } & \multicolumn{4}{|c|}{ Delivery type } & \multirow{3}{*}{ P-Value } \\
\hline & \multicolumn{2}{|c|}{$\begin{array}{l}\text { Caesarean } \\
\text { delivery }\end{array}$} & \multicolumn{2}{|c|}{$\begin{array}{l}\text { Non- } \\
\text { Caesarean } \\
\text { delivery }\end{array}$} & \\
\hline & $\bar{N}$ & $\%$ & $\mathrm{~N}$ & $\%$ & \\
\hline Fetal Distress & & & & & 0.829 \\
\hline No & 588 & 57.2 & 440 & 42.8 & \\
\hline Yes & 64 & 56.1 & 50 & 43.9 & \\
\hline Previous C-Section & & & & & $<0.001$ \\
\hline No & 561 & 53.6 & 485 & 46.4 & \\
\hline Yes & 91 & 94.8 & 5 & 05.2 & \\
\hline Multiple Birth & & & & & 0.945 \\
\hline No & 643 & 57.1 & 483 & 42.9 & \\
\hline Yes & 9 & 56.3 & 7 & 43.8 & \\
\hline Pregnancy-Induced Breathing Difficulty & & & & & 0.993 \\
\hline No & 612 & 57.1 & 460 & 42.9 & \\
\hline Yes & 40 & 57.1 & 30 & 42.9 & \\
\hline Prolonged Labour & & & & & $<0.001$ \\
\hline No & 541 & 70.0 & 232 & 30.0 & \\
\hline Yes & 111 & 30.1 & 258 & 69.9 & \\
\hline Mother's Education & & & & & $<0.001$ \\
\hline Primary and below & 147 & 44.8 & 181 & 55.2 & \\
\hline Secondary & 310 & 55.4 & 250 & 44.6 & \\
\hline Higher & 195 & 76.8 & 59 & 23.2 & \\
\hline Mother's Age: years & & & & & $<0.001$ \\
\hline$<20$ & 185 & 44.5 & 231 & 55.5 & \\
\hline $20-24$ & 160 & 55.2 & 130 & 44.8 & \\
\hline $25-29$ & 198 & 69.0 & 89 & 31.0 & \\
\hline $30+$ & 109 & 73.2 & 40 & 26.8 & \\
\hline Age at Marriage: years & & & & & $<0.001$ \\
\hline$<18$ & 344 & 50.3 & 340 & 49.7 & \\
\hline $18-22$ & 188 & 61.2 & 119 & 38.8 & \\
\hline $23+$ & 120 & 79.5 & 31 & 20.5 & \\
\hline Order of Birth & & & & & 0.062 \\
\hline 1 & 369 & 54.7 & 306 & 45.3 & \\
\hline 2 & 199 & 62.6 & 119 & 37.4 & \\
\hline $3+$ & 84 & 56.4 & 65 & 43.6 & \\
\hline Length of Baby: cm & & & & & 0.029 \\
\hline$<45$ & 457 & 55.1 & 372 & 44.9 & \\
\hline $45+$ & 195 & 62.3 & 118 & 37.7 & \\
\hline Weight of Baby: kg & & & & & 0.894 \\
\hline$<2.5$ & 214 & 57.4 & 159 & 42.6 & \\
\hline $2.5+$ & 438 & 57.0 & 331 & 43.0 & \\
\hline
\end{tabular}

Table 1 Percentage distributions of maternal, socio-demographic and other characteristics by type of delivery and their significance level in northern region of Bangladesh (Continued)

\begin{tabular}{lcccccc}
\hline$<32$ & 486 & 56.0 & 382 & 44.0 & \\
$32+$ & 166 & 60.6 & 108 & 39.4 & \\
Residence & & & & & $<0.001$ \\
Rural & 244 & 67.6 & 117 & 32.4 & \\
Urban & 408 & 52.2 & 373 & 47.8 & \\
Ever had a Child Aborted & & & & & 0.817 \\
No & 631 & 57.2 & 473 & 42.8 & \\
Yes & 21 & 55.3 & 17 & 44.7 & \\
Duration of Taking Balanced Diet & & & & & $<0.001$ \\
Often & 363 & 51.2 & 346 & 48.8 & \\
Once a week & 74 & 49.3 & 76 & 50.7 & \\
Rarely & 215 & 76.0 & 68 & 24.0 & \\
\hline
\end{tabular}

model, the multivariate analysis indicated that fetal distress, previous $\mathrm{C}$-section, mother's age, age at marriage and lower order of birth were significantly independent risk factors for $\mathrm{C}$-section. The risk of having fetal distress and previous $\mathrm{C}$-section had a higher risk as compared to those who did not. The hazard ratios of $\mathrm{C}$-section for older mothers were higher than their younger counterparts. Women who married at the age

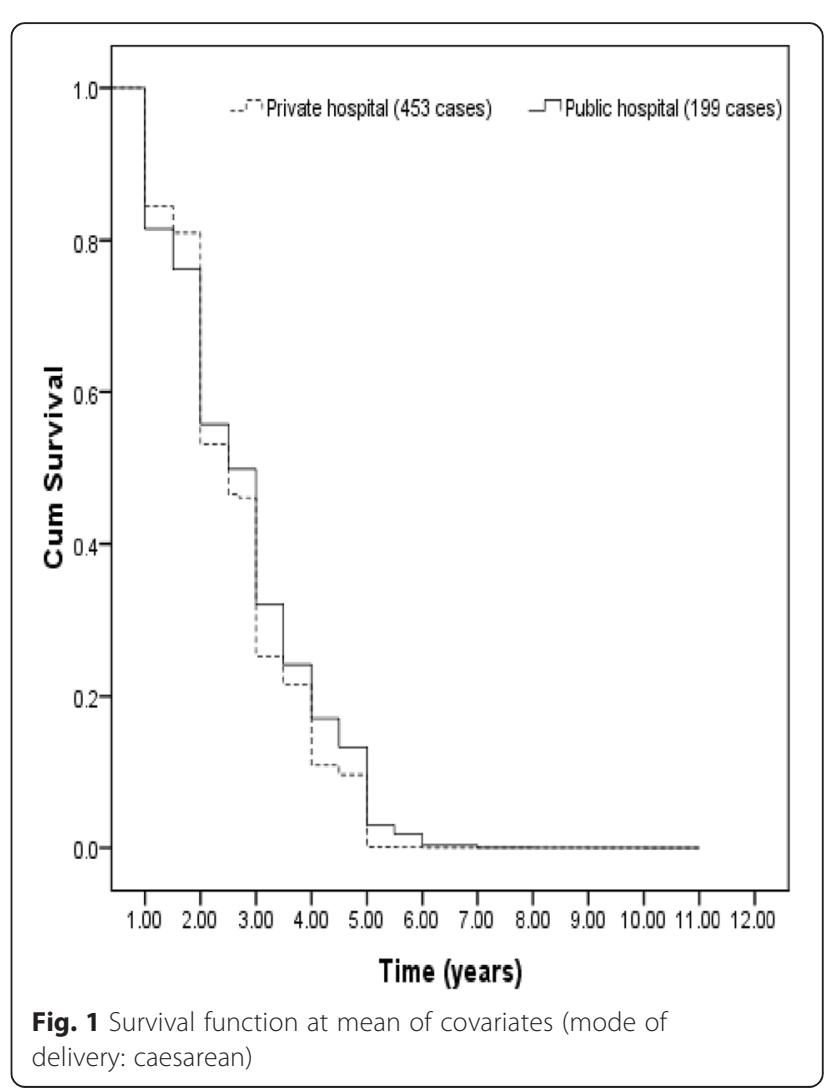


Table 2 Logistic and Cox's regression results of the effects of selected characteristics on C-section: Overall cases

\begin{tabular}{llll}
\hline Selected variables & $\begin{array}{l}\text { Results of logistic } \\
\text { regression analysis }\end{array}$ & & $\begin{array}{l}\text { Results of Cox's } \\
\text { regression analysis }\end{array}$ \\
\cline { 2 - 2 } & $\begin{array}{l}\text { Odds ratio } 95 \% \mathrm{Cl} \\
{[\operatorname{Exp}(\beta)]}\end{array}$ & $\begin{array}{l}\text { Hazard ratio } 95 \% \mathrm{Cl} \\
{[\operatorname{Exp}(\beta)]}\end{array}$ \\
& &
\end{tabular}

Fetal Distress

(No)

Yes

1.00

1.08

$\begin{array}{cc} & 1.00 \\ 0.67-1.76 & 1.01^{*}\end{array}$

$0.52-1.51$

Previous C-section

(No)

1.00

Yes

$20.18^{*}$

$\begin{aligned} & 1.00 \\ 10.46-25.58 & 9.80^{*}\end{aligned}$

Multiple Birth

(No)

Yes

Pregnancy-Induced Breathing Difficulty

(No)

Yes

$\begin{array}{ll} & 1.00 \\ 0.35-3.58 & 1.01\end{array}$

Prolonged Labour

(No)

Yes

$$
0.12-0.23
$$

Mother's Education

(Primary and below)

Secondary

Higher

Mother's Age: years

20-24

25-29

$30+$

1.00

$1.55-3.11 \quad 1.15$

$1.58-4.54 \quad 1.53$

$0.57-2.47$

$0.78-2.41$

Age at Marriage: years

\section{8-22}

Order of Birth

(1)

2

$3+$

$0.49-1.12$

1.00

$0.17-0.64$

0.43

Length of Baby: $\mathrm{cm}$

Weight of Baby: kg

Head Circumferences: $\mathrm{cm}$
Table 2 Logistic and Cox's regression results of the effects of selected characteristics on C-section: Overall cases (Continued)

\begin{tabular}{|c|c|c|c|c|}
\hline $32+$ & 1.084 & $0.76-1.54$ & 1.02 & $0.57-1.89$ \\
\hline \multicolumn{5}{|l|}{ Residence } \\
\hline (Rural) & 1.00 & & 1.00 & \\
\hline Urban & 0.854 & $0.61-1.91$ & 0.51 & $0.28-1.18$ \\
\hline \multicolumn{5}{|l|}{$\begin{array}{l}\text { Ever had a Child } \\
\text { Aborted }\end{array}$} \\
\hline (No) & 1.00 & & 1.00 & \\
\hline Yes & 0.57 & $0.25-1.33$ & 0.34 & $0.16-1.51$ \\
\hline \multicolumn{5}{|l|}{$\begin{array}{l}\text { Duration of Taking } \\
\text { Balance Diet }\end{array}$} \\
\hline (Often) & 1.00 & & 1.00 & \\
\hline Once a week & $1.45^{*}$ & $0.95-2.22$ & 1.20 & $0.54-2.22$ \\
\hline Rarely & $1.87^{*}$ & $1.24-2.81$ & 1.45 & $0.69-2.07$ \\
\hline Intercept & -0.25 & & $\begin{array}{l}-2 \text { log } \\
\text { likelihood }\end{array}$ & 13765.19 \\
\hline-2 log likelihood & 2997.81 & & $\begin{array}{l}\text { Modelchi- } \\
\text { square }\end{array}$ & $398.94^{*}$ \\
\hline Cox \&Snell $R^{2}$ & 0.54 & & $\begin{array}{l}\text { Degrees } \\
\text { of freedom }\end{array}$ & 21 \\
\hline Nagelkerke $R^{2}$ & 0.57 & & & \\
\hline AIC & 3031.82 & & $\mathrm{AIC}$ & 13799.19 \\
\hline
\end{tabular}

of 18-22 years had a lower risk of C-section as compared to women who married at an early age ( $<18$ years) and married at an older age ( 23 years and above). Similarly, increased parity (order of birth) had a lower risk as compared to lower parity (first order of birth) for C-section.

To examine the Caesarean delivery with associated risk factors by types of health facilities, separate models were constructed for deliveries in private and public hospitals (Tables 3 and 4). Based on the results of logistic regression alone, it was found that women who have related complications around delivery (previous C-section, prolonged labour) and delivered in public hospitals tend to have higher risk of $\mathrm{C}$-section than those who delivered in private hospitals. In public hospitals, the highest odds ratios for caesarean delivery were seen in women aged 30 years and above $(\mathrm{OR}=2.96, \mathrm{CI}=0.94-7.32)$ as compared to those aged 25 years and below. Similarly, first and second-born babies had higher odds of being delivered by $\mathrm{C}$-section $(\mathrm{OR}=0.52, \mathrm{CI}=0.16-1.83)$ as compared to third or above for deliveries occurring in private hospitals. For the length of baby, compared between the two facilities, it is found that this determinant factor was also less important in public hospitals as compared to private hospital. By comparing the place of delivery, it was a significant determinant of C-section for women delivering in private hospitals, with the 
Table 3 Logistic and Cox's regression results of the effects of selected characteristics on C-section: Private hospitals

\begin{tabular}{llll}
\hline Selected variables & \multicolumn{3}{l}{ Private hospitals } \\
\cline { 2 - 4 } & $\begin{array}{l}\text { Odds ratio } \\
\text { [Exp }(\beta)]\end{array}$ & $\begin{array}{l}\text { Hazard ratio } \\
{[\operatorname{Exp}(\beta)]}\end{array}$ & $95 \% \mathrm{Cl}$ \\
\hline
\end{tabular}

Fetal Distress

(No)

Yes

1.00

1.32

1.00

Previous C-section

(No)

Yes

1.00

6.72

$1.04-2.51 \quad 1.03$

Multiple Birth

(No)

1.00

Yes

Pregnancy-Induced Breathing Difficulty

(No)

Yes

Prolonged Labour

(No)

Yes

Mother's Education

(Primary and

below)

Secondary

Higher

Mother's Age:

years

$(<20)$

20-24

25-29

$30+$

Age at Marriage:

years

$(<18)$

18-22

$23+$

Order of Birth

(1)

2

$3+$

Length of Baby's: $\mathrm{cm}$

$45+$

Weight of Baby's: kg

$2.5+$

1.00

2.26

0.82-1.71

$3.48-12.05 \quad 2.21$

$1.01-4.03$

$0.52-2.47$

$0.98-2.03 \quad 1.13$

$1.00 \quad 1.00$

$0.02^{*} \quad 0.01-0.08 \quad 0.82$

$0.28-1.48$

0.07-1.41

$0.09-1.78$

$1.03-2.23$

$0.22-3.57 \quad 1.52^{*}$
Table 3 Logistic and Cox's regression results of the effects of selected characteristics on C-section: Private hospitals (Continued)

Head Circumferences:

$\mathrm{cm}$

$32+$

1.00

1.00

$\begin{array}{lll}0.56 & 0.19-1.45 & 0.38\end{array}$

$0.15-1.38$

Residence

(Rural)

1.00

1.00

Urban

$4.60^{*}$

$1.27-12.10 \quad 1.93$

$0.47-2.41$

Ever had a Child

Aborted

(No)

1.00

1.00

0.34

$0.03-1.83 \quad 0.23$

$0.05-1.12$

Duration of Taking

Balance Diet

(Often)

Once a week

1.00

1.00

Rarely

2.45

$0.65-9.63 \quad 1.28$

$0.59-2.21$

Intercept

8.23

$1.18-14.32 \quad 3.31$

$1.42-5.63$

-2 log likelihood

4.38

$-2 \log$

likelihood

1123.01

Model

5022.35

Cox \&Snell $R^{2}$

0.51

chi-square

$189.47^{*}$

Degrees of 21

Nagelkerke $\mathrm{R}^{2}$

0.53

AlC

1157.01 freedom

${ }^{*} P<0.05$, significant risk factors in the model; $\mathrm{Cl}=$ confidence interval; parentheses indicate the reference categories

strongest risk shown for women residing in urban areas. Finally, a C-section was 1.73 times more likely to occur in public hospitals to women who rarely take a balanced diet. Conversely, to determine independent risk factors for survival time, the Cox's regression model showed that maternal age, age at marriage and parity were only statistically significant with $\mathrm{C}$-section in both health facilities.

To identify the best regression model for caesarean delivery, we carried out a stepwise regression analysis on the variables in Table 2 . In the overall and different hospitals, the most influential significant variables are listed in Tables 5 and 6 respectively. By the stepwise selection, the logistic and Cox's regression analysis reveals that seven and five remained significant independent risk factors to predict which patients were at highest risk for caesarean delivery. The most common factors were previous C-section, mother's age and order of birth in both analyses (Table 5 ). From the different health facilities in Table 6, the logistic regression analysis indicated in a stepwise manner the following risk factors: prolonged labour, length of baby more than $45 \mathrm{~cm}$, urban residence and lower birth order were the most 
Table 4 Logistic and Cox's regression results of the effects of selected characteristics on C-section: Public hospitals

\begin{tabular}{llll}
\hline Selected variables & \multicolumn{3}{l}{ Public hospitals } \\
\cline { 2 - 4 } & $\begin{array}{l}\text { Odds ratio } \\
{[\operatorname{Exp}(\beta)]}\end{array}$ & $\begin{array}{l}\text { Hazard ratio } \\
{[\operatorname{Exp}(\beta)]}\end{array}$ & $95 \% \mathrm{Cl}$ \\
\hline
\end{tabular}

Fetal Distress

(No)

Yes

1.00

1.57

$\begin{aligned} & 1.00 \\ 0.82-2.11 & 1.23^{*}\end{aligned}$

Previous C-section

(No)

Yes

Multiple Birth

(No)

Yes

Pregnancy-Induced Breathing Difficulty

(No)

Yes

Prolonged Labour

(No)

Yes

Mother's Education

(Primary and below)

Secondary

Higher

Mother's Age: years

$(<20)$

1.00

$8.98^{*}$

1.00
$5.21-10.51 \quad 3.75$

1.00

1.59

1.00

$0.79-2.74 \quad 1.30$

20-24

25-29

$30+$

Age at Marriage: years

18-22

$23+$

Order of Birth

(1)

2

$3+$

Length of Baby's: cm

$45+$

Weight of Baby's: kg

$(<2.5)$

$2.5+$

Head Circumferences:

$\mathrm{cm}$

$(<32)$

$32+$
1.00

0.71

$0.29^{*}$

1.00

$1.49^{*}$

1.00

0.75
$0.46-1.12 \quad 0.65$

$\begin{array}{cc} & 1.00 \\ 0.46-1.34 & 0.55^{*}\end{array}$

$0.19-1.01 \quad 0.22^{*}$

$0.95-2.47=1.22$

1.00

$0.13-1.81$

$0.22-1.25$

$0.09-1.06$

$0.16-3.29$
$0.08-2.17$

$1.25-5.36$

$0.78-2.58$

$0.55-1.84$

$0.07-1.62$

$0.72-2.14$

$0.24-2.36$

$1.02-2.14$

$1.28-3.20$

$1.32-4.17$

$0.24-1.50$

$0.41-1.62$

Discussion

The findings of this study provide us an insight into the impact of maternal, socio-demographic and relevant factors on C-section in the northern region of Bangladesh. The analysis of the C-section deliveries for the private and public hospitals substantiates this concern. The rate of $\mathrm{C}$-section was higher in private hospitals as compared to public hospitals. Past studies in different countries found that the rate of caesarean delivery in private hospitals is also higher than public hospitals [36, 37]. It seems that the private practice of the doctors and the

Nagelkerke R2 $\quad 0.55$

${ }^{*} P<0.05$, significant risk factors in the model; $\mathrm{Cl}=$ confidence interval; parentheses indicate the reference categories

significant determinants of caesarean section in private hospitals, while for public hospitals prolonged labour, previous C-section, and higher mother's educational level were the most important risk factors for determiBangladesh. In a forgoing study using the Cox's gression model by stepwise method, it is also found that mother's age, age at marriage and order of birth were the common most influential variables among the selected variables in private and public patients. In AIC is lower in parametric (logistic) model as compare to semi parametric (Cox's) model. Therefore, the results indicated that the logistic model is the most efficient than Cox's model for determinant the risk factors for caesarean delivery in multivariable analysis.
Table 4 Logistic and Cox's regression results of the effects of selected characteristics on C-section: Public hospitals (Continued)

Residence

(Rural)

Ever had a Child

Aborted

(No)

1.00

0.48

$0.16-1.66 \quad 0.31$

$0.17-1.11$

Duration of Taking

(Often)

1.00

$0.82-2.59 \quad 1.11$

$0.41-2.31$

$\begin{array}{lll}1.73 & 0.98-2.83 & 1.42\end{array}$

$0.71-3.21$

$-2 \log$

likelihood

Model 223.72

Degrees of 21 freedom 
Table 5 Stepwise regression results of the effects of selected characteristics on C-section: Overall cases

\begin{tabular}{|c|c|c|}
\hline \multicolumn{3}{|c|}{ Results of logistic regression by stepwise selection } \\
\hline $\begin{array}{l}\text { Most influential variables among } \\
\text { selected variables }\end{array}$ & Odds ratio $[\operatorname{Exp}(\beta)]$ & $95 \% \mathrm{Cl}$ \\
\hline \multicolumn{3}{|l|}{ Prolonged Labour } \\
\hline (No) & 1.00 & \\
\hline Yes & $0.17^{*}$ & $0.12-0.23$ \\
\hline \multicolumn{3}{|l|}{ Previous C-section } \\
\hline (No) & 1.00 & \\
\hline Yes & $20.53^{*}$ & $10.23-24.92$ \\
\hline \multicolumn{3}{|l|}{ Mother's Education } \\
\hline (Primary and below) & 1.00 & \\
\hline Secondary & $2.04^{*}$ & $1.49-3.01$ \\
\hline Higher & $2.50^{*}$ & $1.48-4.31$ \\
\hline \multicolumn{3}{|l|}{ Mother's Age: years } \\
\hline$(<20)$ & 1.00 & \\
\hline $20-24$ & 1.35 & $0.82-1.82$ \\
\hline $25-29$ & $2.85^{*}$ & $1.42-4.12$ \\
\hline $30+$ & $5.76^{*}$ & $2.12-12.41$ \\
\hline \multicolumn{3}{|l|}{ Order of Birth } \\
\hline$(1)$ & 1.00 & \\
\hline 2 & 0.70 & $0.48-1.01$ \\
\hline $3+$ & $0.31^{*}$ & $0.12-0.58$ \\
\hline \multicolumn{3}{|l|}{ Duration of Taking Balance Diet } \\
\hline (Often) & 1.00 & \\
\hline One day per week & $1.50^{*}$ & $1.10-2.52$ \\
\hline Rarely & $1.87^{*}$ & $1.32-2.85$ \\
\hline \multicolumn{3}{|l|}{ Length of Baby's: cm } \\
\hline$(<45)$ & 1.00 & \\
\hline $45+$ & $1.46^{*}$ & $1.11-2.24$ \\
\hline Constant & $0.66^{*}$ & $0.23-1.57$ \\
\hline \multicolumn{3}{|l|}{$\begin{array}{l}\text { Results of Cox's regression by } \\
\text { stepwise selection }\end{array}$} \\
\hline $\begin{array}{l}\text { Most influential variables } \\
\text { among selected variables }\end{array}$ & $\begin{array}{l}\text { Hazard ratio } \\
{[\operatorname{Exp}(\beta)]}\end{array}$ & $95 \% \mathrm{Cl}$ \\
\hline \multicolumn{3}{|l|}{ Mother's Age: years } \\
\hline$(<20)$ & 1.00 & \\
\hline $20-24$ & $1.32^{*}$ & $1.10-3.23$ \\
\hline $25-29$ & $1.55^{*}$ & $1.21-2.51$ \\
\hline $30+$ & $2.25^{*}$ & $1.25-3.35$ \\
\hline \multicolumn{3}{|l|}{ Age at Marriage: years } \\
\hline$(<18)$ & 1.00 & \\
\hline $18-22$ & $0.69^{*}$ & $0.24-1.87$ \\
\hline $23+$ & $1.10^{*}$ & $0.54-2.56$ \\
\hline \multicolumn{3}{|l|}{ Order of Birth } \\
\hline$(1)$ & 1.00 & \\
\hline
\end{tabular}

Table 5 Stepwise regression results of the effects of selected characteristics on C-section: Overall cases (Continued)

\begin{tabular}{lcc}
\hline 2 & $0.40^{*}$ & $0.21-1.36$ \\
$3+$ & $0.34^{*}$ & $0.16-1.53$ \\
Fetal Distress & & \\
$(\mathrm{No})$ & 1.00 & $0.69-2.14$ \\
Yes & $1.21^{*}$ & \\
Abdominal Operation & & \\
(No) & 1.00 & $3.28-18.62$ \\
Yes & $10.20^{*}$ & \\
${ }^{*} P<0.05$, significant risk factors in the model; $\mathrm{Cl}=$ confidence interval; \\
parentheses indicate the reference categories
\end{tabular}

financial motive of the private hospitals may be playing some important role in determining the caesarean rates. This statement is supported by the previous studies [37]. The result from the logistic regression analysis showed that previous $\mathrm{C}$-section, prolonged labour (more than $12 \mathrm{~h}$ ), maternal education level, mother's age of more than 25 years, low birth order, length of baby more than $45 \mathrm{~cm}$ and irregular intake of a balanced diet were important determinants of C-section. Conversely, two newly independent risk factors (fetal distress and age at marriage) were also found to determinants of $\mathrm{C}$-section by the Cox's regression model. Furthermore, the association of these determinants with $\mathrm{C}$-section varied by the different health facilities. By the stepwise selection in logistic regression analysis, we confirmed that demographic characteristics such as length of baby, place of residence and order of birth were more important in private facilities whereas mothers complication such as prolonged labour, previous $\mathrm{C}$-section were more significant determinants in public facilities. Moreover, the Cox's model found that only one factor which is included in mothers' complication as fetal distress was independent risk factor for $\mathrm{C}$-section in public facilities. Therefore, as shown in these findings, we have expected the rate of C-section will be higher in public patients than in private patients but the observed result shows the inverse.

In the multivariate analysis, educational level, maternal age and parity were found to be the significant nonclinical factors as the ones being the best efficient models in the logistic model. Our results also confirmed by other studies [38, 39]. The findings of the present study may indicate that educated women tend to delay giving birth, thus increasing their likelihood of having $\mathrm{C}$-section. In the previous study, it was found that mother's education is a proxy of socio-economic variable and it is associated with C-section [40]. In 2001, Ecker et al. [14] cited changes in the childbearing population as a significant cause of the increase of Caesarean birth rates. It is also established that age of 
Table 6 Stepwise regression results of the effects of selected characteristics on C-section: Private \& Public hospitals

\begin{tabular}{|c|c|c|c|c|c|}
\hline \multicolumn{6}{|c|}{ Results of logistic regression by stepwise selection } \\
\hline \multirow{2}{*}{$\begin{array}{l}\text { Most influential variables among } \\
\text { selected variables }\end{array}$} & \multicolumn{2}{|l|}{ Private hospital } & \multirow{2}{*}{$\begin{array}{l}\text { Most influential variables among } \\
\text { selected variables }\end{array}$} & \multicolumn{2}{|l|}{ Public hospital } \\
\hline & Odds ratio $[\operatorname{Exp}(\beta)]$ & $95 \% \mathrm{Cl}$ & & Odds ratio $[\operatorname{Exp}(\beta)]$ & $95 \% \mathrm{Cl}$ \\
\hline \multicolumn{3}{|l|}{ Prolonged Labour } & \multicolumn{3}{|l|}{ Prolonged Labour } \\
\hline (No) & 1.00 & & (No) & 1.00 & \\
\hline Yes & $0.03^{*}$ & $0.01-0.08$ & Yes & $0.21^{*}$ & $0.11-0.27$ \\
\hline \multicolumn{3}{|l|}{ Length of Baby: cm } & \multicolumn{3}{|l|}{ Previous C-section } \\
\hline$(<45)$ & 1.00 & & (No) & 1.000 & \\
\hline $45+$ & $0.17^{*}$ & $0.03-0.41$ & Yes & $7.74^{*}$ & $4.12-9.36$ \\
\hline \multicolumn{3}{|l|}{ Residence } & \multicolumn{3}{|l|}{ Mother's Education } \\
\hline (Rural) & 1.00 & & (Primary and below) & 1.00 & \\
\hline \multirow[t]{2}{*}{ Urban } & \multirow[t]{2}{*}{$4.07^{*}$} & \multirow[t]{2}{*}{$1.31-10.11$} & Secondary & 1.43 & $1.10-2.73$ \\
\hline & & & Higher & $2.59^{*}$ & $1.82-5.93$ \\
\hline \multicolumn{6}{|l|}{ Order of Birth } \\
\hline (1) & 1.00 & & & & \\
\hline 2 & $0.89^{*}$ & $0.23-1.21$ & \multirow[t]{3}{*}{ Constant } & \multirow[t]{3}{*}{$0.36^{*}$} & \multirow[t]{3}{*}{$0.12-1.67$} \\
\hline $3+$ & $0.23^{*}$ & $0.12-1.54$ & & & \\
\hline Constant & $8.64^{*}$ & $2.54-16.82$ & & & \\
\hline \multicolumn{6}{|c|}{ Results of Cox's regression by stepwise selection } \\
\hline \multirow{2}{*}{$\begin{array}{l}\text { Most influential variables among } \\
\text { selected variables }\end{array}$} & Private hospital & & \multirow{2}{*}{$\begin{array}{l}\text { Most influential variables among } \\
\text { selected variables }\end{array}$} & \multicolumn{2}{|l|}{ Public hospital } \\
\hline & Hazard ratio $[\operatorname{Exp}(\beta)]$ & $95 \% \mathrm{Cl}$ & & Hazard ratio $[\operatorname{Exp}(\beta)]$ & $95 \% \mathrm{Cl}$ \\
\hline \multicolumn{3}{|l|}{ Mother's Age: years } & \multicolumn{3}{|l|}{ Mother's Age: years } \\
\hline$(<20)$ & 1.00 & & $(<20)$ & 1.00 & \\
\hline $20-24$ & $1.04^{*}$ & $0.57-2.14$ & $20-24$ & $1.37^{*}$ & $0.65-2.36$ \\
\hline $25-29$ & $1.31^{*}$ & $0.45-2.21$ & $25-29$ & $2.17^{*}$ & $1.15-3.87$ \\
\hline $30+$ & $2.25^{*}$ & $1.20-4.12$ & $30+$ & $2.57^{*}$ & $1.36-4.13$ \\
\hline \multicolumn{3}{|l|}{ Age at Marriage: years } & \multicolumn{3}{|l|}{ Age at Marriage: years } \\
\hline$(<18)$ & 1.00 & & $(<18)$ & 1.00 & \\
\hline $18-22$ & $1.67^{*}$ & $1.02-3.25$ & $18-22$ & $0.61^{*}$ & $0.32-1.19$ \\
\hline $23+$ & $2.35^{*}$ & $1.26-4.36$ & $23+$ & $1.21^{*}$ & $0.49-2.58$ \\
\hline \multicolumn{3}{|l|}{ Order of Birth } & \multicolumn{3}{|l|}{ Order of Birth } \\
\hline (1) & 1.00 & & (1) & 1.00 & \\
\hline 2 & $0.38^{*}$ & $0.04-1.13$ & 2 & $0.65^{*}$ & $0.13-1.21$ \\
\hline $3+$ & $0.23^{*}$ & $0.11-1.10$ & $3+$ & $0.41^{*}$ & $0.18-1.20$ \\
\hline Fetal Distress & & & Fetal Distress & & \\
\hline (No) & Not found & & (No) & 1.00 & \\
\hline Yes & & & Yes & $1.51^{*}$ & $0.84-3.10$ \\
\hline
\end{tabular}

${ }^{*} P<0.05$, significant risk factors in the model; $\mathrm{Cl}=$ confidence interval; parentheses indicate the reference categories

mother is closely related to C-section [40]. Nassar \& Sullivan [45] suggested that age and parity (order of birth) alone account for most demographic changes because there is a high primary caesarean rate for first birth to women 30 years age and older. Mothers with low birth order who undergo C-section, explained that the choice were made mainly because of their greater risk of pregnancy and delivery-related complications
$[37,43,44]$. Therefore, it has been suggested that delivery by caesarean birth is a complicated health issue on a country level and also a global perspective. In addition, place of residence is one of the most important factors in determining whether to perform a C-section in private or public hospital, which is consistent with the findings of other studies $[41,44]$ have also found that there is a strong association between $\mathrm{C}$-section 
and place of residence. It seems that women residing in urban areas of the northern region were more likely to undergo $\mathrm{C}$-section in private hospitals. This indicates the importance of social status in determining the type of delivery and also pertains to issues related to disparities in the distribution of health facilities in the country with respect to several studies [45]. Furthermore, numerous socio-economic and cultural factors influence the decision on pattern of feeding and balance diet that may influence the type of delivery. As a point of view, duration of taking balanced diet was considered as an independent variable and the study found that irregular intake of a balanced diet is a significant determinant for caesarean delivery from logistic regression analysis. As also previously mentioned, the significant non-clinical factor found in this study was age at marriage. Therefore, it may indicate that adding more proteins, carbohydrate, vitamins in daily intake will be more beneficial for pregnant women to avoid $\mathrm{C}$-section and decreasing late marriage of the study population for C-section.

\section{Conclusion}

The above discussion leads to the conclusion that delivery by $\mathrm{C}$-section is a complicated health issue. Efforts to reduce $\mathrm{C}$-section birth in developing countries like the northern region of Bangladesh will require a comprehensive approach to address patients' variables, caregiver practices and hospital policies. In order to address the reduction of caesarean rate in the northern region, significant factors such as previous $\mathrm{C}$-section, prolonged labour, maternal educational level, age at marriage, mother's age of more than 25 years, low birth order, length of baby more than $45 \mathrm{~cm}$ and irregular intake of a balanced diet can be considered to be predictors for $\mathrm{C}$-section. Finally, from the statistical point of view, this study also suggests that these factors may influence the health-seeking behavior of women. Additionally, for determinants of risk factors, the evaluation criteria on AIC, this study imply that logistic regression model can be lead to more precise results as an alternative for the Cox model. Thus, the following steps may be recommended in view of the observed findings:

i. In the study we found that the rate of caesarean delivery is lower in public hospitals than private hospitals. Therefore, medical audit, quality assessment and supportive supervision should be considered to improve the quality of care in a private hospital that is likely to minimize C-section rate.

ii. The result also shows that less than 19 years and more than 25 years old of mothers age are at higher pregnancy risks for $\mathrm{C}$-section. Thus, age group 20 to 24 should be safer for normal delivery. However, future research should review maternal age when examining predictors of caesarean birth.

iii. Encouraging pregnant women to take a balanced and nutritional diet may be beneficial.

iv. Health awareness and educational programs should be given to focus on educating women, on appropriate delivery types when their health and specific status will be known.

v. Provide complete and reliable information to the mothers so that they do not opt for $\mathrm{C}$-section in a state of panic or ignorance.

vi. Universities and schools who educate health team (doctors, midwives, and nurses) offer topic that directly deal with this subject.

vii. Further research at the national level with other medical procedures is highly recommended to figure out the extent of this problem in Northern region of Bangladesh.

viii.Moreover, Government should be given more attention to monitor hospital data and corresponding strategies.

\section{Competing interests}

The authors declare that they have no competing interest.

\section{Authors' contributions}

MR executed the questionnaire design, testing of interventions, analyzed data and prepared the manuscript. AAS, AS and RS participated in intervention development, editing, additional ideas and analysis activities. RMT contributed to subsequent modifications, designed and executed the overall research study. All authors contributed to the drafting of the paper and approved the final submitted version. MR, AAS and RMT are the guarantors. All authors had full access to all the data in the study, including statistical reports and tables, and can take responsibility for the integrity of the data and the accuracy of the data analysis.

\section{Acknowledgments}

We wish to thank the University of Malaya for the financial assistance in this project under UMRG grant (RG105-10AFR).

\section{Author details}

${ }^{1}$ University of Rajshahi, Rajshahi, Bangladesh. ${ }^{2}$ Centre for Foundation Studies in Science, University of Malaya, Kuala Lumpur, Malaysia. ${ }^{3}$ Department of Geography, Faculty of Arts and Social Sciences, University of Malaya, Kuala Lumpur, Malaysia. ${ }^{4}$ Department of Obstetrics and Gynaecology, Faculty of Medicine, University of Malaya, Kuala Lumpur, Malaysia.

Received: 29 April 2015 Accepted: 26 June 2015

Published online: 31 July 2015

\section{References}

1. Kabir MA, Goh K-L, Khan MMH, Al-Amin AQ, Azam MN. Safe delivery practices: experience from cross-sectional data of Bangladeshi women. Asia Pac J Public Health. 2012 (on line published: http://aph.sagepub. com/content/early/2012/02/23/1010539512437401).

2. Bangladesh Demographic and Health Survey (BDHS). Dhaka, Bangladesh: Mitra and associates. 2011.

3. BMMS. Bangladesh maternal mortality and health care survey 2010: summary of key findings and implications. Dhaka, Bangladesh. 2010. 1-12.

4. Gomes UA, Silva AA, Bettiol H, Barbieri MA. Risk factors for the increasing caesarean section rate in Southeast Brazil: a comparison of two birth cohorts, 1978-1979 and 1994. Int J Epidemio. 1999;28:687-94.

5. Leung GM, Lam TH, Thach TQ, Wan S, Ho LM. Rates of caesarean birth in Hong Kong: 1987-1999. Birth. 2001;28:166-72. 
6. Kassak KM, Ali AM, Abduallah AM. Opting for caesarean: what determines the decision? J Public Admin Manage. 2009;14(1):100-22.

7. Belizán JM, Althabe F, Barros FC, Alexander S, Showalter E, Griffin A, et al. Rates and implications of caesarean sections in Latin America: ecological study. Br Med J. 1999;319:1397-400.

8. Murray SF. Relation between private health insurance and high rates of caesarean section in Chile: qualitative and quantitative study. Br Med J. 2000;321:1501-5.

9. Martin JA, Park MM, Sutton PD. Births: preliminary data for 2001. National Vital Statistical Report. 2002;50:1-20

10. Ravindran J. Rising caesarean section rates in public hospitals in Malaysia 2006. Med J Malaysia. 2008;63(5):434-5.

11. World Health Organization (WHO). Appropriate technology for birth. Lancet. 1985;2:436-7.

12. Savage W. The caesarean section epidemic. J Obstet Gynaecol. 2000:20:223-5

13. Parrish KM, Holt VL, Easterling TR, Connell FA, LoGerfo JP. Effect of changes in maternal age, parity, and birth weight distribution on primary caesarean delivery rates. J Am Med Assoc. 1994;271:443-7.

14. Ecker JL, Chen KT, Cohen AP, Riley LE, Lieberman ES. Increased risk of caesarean delivery with advancing maternal age: indications and associated factors in nulliparous women. Am J Obstet Gynaecol. 2001;185:883-7.

15. Peipert JF, Bracken MB. Maternal age: an independent risk factor for caesarean delivery. Obstet Gynaecol. 1993;81:200-5.

16. Mossialos E, Allin S, Karras K, Davaki K. An investigation of caesarean section in three greek hospitals: the impact of financial incentives and convenience. Eur J Public Health. 2005;15:288-95.

17. Cnattingius R, Cnattingius S, Notzon FC. Obstacles to reducing caesarean rates in a low-caesarean setting: the effect of maternal age, height, and weight. Obstet Gynaecol. 1998;92(4 Pt 1):501-6.

18. Gould JB, Davey B, Stafford RS. Socioeconomic differences in rates of caesarean section. N Engl J Med. 1989:321:233-9.

19. Skalkidis Y, Petridou E, Papathoma E, Revinthi K, Tong D, Trichopoulos D. Are operative delivery procedures in Greece socially conditioned? Int J Qual Health Care. 1996:8:159-65.

20. Parazzini F, Pirotta N, La Vecchia C, Fedele L. Determinants of caesarean section rates in Italy. BJOG: Int J Obstet Gynaecol. 1992;99:203-6.

21. Tatar M, Gunalp S, Somunoglu S, Demirol A. Women's perceptions of caesarean section: reflections from a Turkish teaching hospital. Soc Sci Med. 2000;50:1227-33.

22. Hurst M, Sumney PS. Childbirth and social class: the case of caesarean delivery. Soc Sci Med. 1984;18:621-31.

23. Taffel SM. Caesarean delivery in the United States, 1990. Vital Health Statistics. 1994;51:1-24

24. Spaans WA, Sluijs MB, Van Roosmalen J, Bleker O. Risk factors at caesarean section and failure of subsequent trial of labour. Eur J Obstet Gynaeco Reprod Biol. 2002;100:163-6.

25. Lynch CM, Kearney R, Turner MJ. Maternal morbidity after elective repeat caesarean section after two or more previous procedures. Eur J Obstet Gynaecol Reprod Biol. 2002;4320:1-4.

26. Signorelli C, Cattaruzza MS, Osborn JF. Risk factors for caesarean section in Italy: results of a multicentre study. Public Health. 1995;109:191-9.

27. Wilkinson C, Mcllwaine G, Boulton-Jones C, Cole S. Is a rising caesarean section rate inevitable? BJOG: Int J Obstet Gynaecol. 1998:105:45-52.

28. Hall M. When a woman asks for a caesarean section. Br Med J. 1987;294:201-2.

29. Mould TA, Chong S, Spencer JAD, Gallivan S. Women's involvement with the decision preceding their caesarean section and their degree of involvement. BJOG: Int J Obstet Gynaecol. 1996;103:1074-7.

30. Shearer EL. Caesarean section: medical benefits and costs. Soc Sci Med. 1993:37:1223-31.

31. Barros FC, Vaughan JP, Victora CG, Huttly SR. Epidemic of caesarean sections in Brazil. Lancet. 1991;338:167-9.

32. Bertollini R, DiLallo D, Spadea T, Perucci C. Caesarean section rates in Italy by hospital payment mode: an analysis based on birth certificates. Am J Public Health. 1992:82:257-61.

33. Sufang G, Padmadas SS, Fengmin Z, Brown JJ, Stones RW. Delivery settings and caesarean section rates in China. Bulletin of World Health Org, Geneva. 2007:85:10.
34. Mishra US, Ramanathan M. Delivery-related complications and determinants of caesarean section rates in India. Health Policy Plan. 2002;17:90-8.

35. Therneau T, Grambsch P. Modelling survival data: extending the cox model. New York: Springer-Verlag; 2000. p. 14

36. Green MS, Symons MJ. A comparison of the logistic risk function and the proportional hazards model in prospective epidemiological studies. J Chron Dis. 1983;36(10):715-24.

37. Khawaja M, Jurdi R, Kabakian T. Rising trends in caesarean section rates in Egypt. Birth. 2004;31(1):12-6.

38. Parkhurst JO, Rahman SA. Life saving or money wasting? Perceptions of caesarean sections among users of services in rural Bangladesh. Health Policy. 2007;80:392-401.

39. Abu-Heija AT, Jallad MF, Abukteish F. Obstetrics and prenatal outcome for pregnancies after the age of 45. J Obstet Gynaecol. 1999;19:486-8.

40. Padmadas S, Kumar S, Nair S, Kumari A. Caesarean section delivery in Kerala, India: evidence from a national family health survey. Soc Sci Med. 2000;51:511-21.

41. Nassar N, Sullivan E. Australia's Mothers and Babies, 1999, AlHW Cat. no. PER19, Perinatal Statistics Series no. 11, AlHW National Perinatal Statistics Unit, Sydney. 2001

42. Webster L, Daling J, Mcfarlane C, Ashley D, Warren C. Prevalence and determinants of caesarean section in Jamaica. J Bio Sci. 1992:24:515-25.

43. Stanton CK, Holtz SA. Levels and trends in caesarean birth in the developing world. Stud Fam Plann J. 2006:37(1):41-8.

44. Villar J, Valladares E, Wojdyla D, Zavaleta N, Carroli G, Velazco A, et al. Caesarean delivery rates and pregnancy outcomes: the 2005 WHO global survey on maternal and prenatal health in Latin America. Lancet. 2006:367(9525):1819-29.

45. Chaudhury N, Hammer JS. Ghost doctors: absenteeism in Bangladesh health facilities, Policy Research Working Paper. Washington, D.C: World Bank; 2003. p. 3065 .

\section{Submit your next manuscript to BioMed Central and take full advantage of:}

- Convenient online submission

- Thorough peer review

- No space constraints or color figure charges

- Immediate publication on acceptance

- Inclusion in PubMed, CAS, Scopus and Google Scholar

- Research which is freely available for redistribution

Submit your manuscript at www.biomedcentral.com/submit 